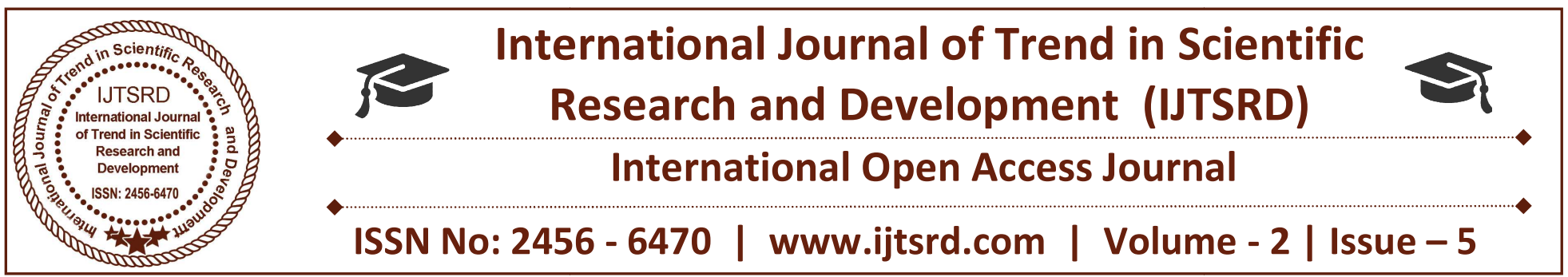

\title{
A Survey Analysis On Diabetes
}

\author{
R. Rupadevi ${ }^{1}$, N. Sushma ${ }^{1}$, D. Divya ${ }^{2}$ \\ ${ }^{1}$ Lecturer, Department of Biotechnology, ${ }^{2}$ Lecturer, Department of Zoology \\ St. Ann's College for Women \\ Mehdipatnam, Hyderabad, Telangana, India
}

\begin{abstract}
Healthcare is such a wide and extensive area of research wherein diabetes is such a deadly disease which hampers a common man life at the extreme end. Under healthcare, there is always a chance for uncertainty and imprecision under various aspects of medical diagnosis process. This paper reviews various existing methodologies and techniques used for early diagnosis of diabetes mellitus which works like risk alarms to save human life. This survey gives us current state of research in diagnosing disease like diabetes and helps us to find out difficulties with the
\end{abstract} existing systems.

Keywords: Diabetes Mellitus, Glucose, Blood, Insulin

\section{INTRODUCTION}

After a century of medical progress, people nowadays live longer with diabetes than ever before. However, current preventative approaches, compounded in part by increased life-expectancy, are failing to reduce the prevalence of diabetes. Evidence indicates that certain glucose-lowering medications can improve vascular outcomes in some people with type 2 diabetes, which, together with better understanding of using multiple therapies concurrently, offers opportunities for beneficial personalization of medication regimens

Although there are numerous other promising advances in pharmacotherapy's and biotechnology, these will probably be unaffordable for most people with diabetes globally. Therefore, effective national public health approaches will be essential to reducing the incidence of diabetes and its associated burdens; these may entail politically controversial measures to change unhealthy lifestyle behaviours.

(hyperglycemia). This is because the body does not produce enough insulin, produces no insulin, or has cells that do not respond properly to the insulin the pancreas produces. This results in too much glucose building up in the blood. This excess blood glucose eventually passes out of the body in urine. So, even though the blood has plenty of glucose, the cells are not getting it for their essential energy and growth requirements.

Diabetes, describes a group of metabolic diseases in which the person has high blood glucose (blood sugar), either because insulin production is inadequate, or because the body's cells do not respond properly to insulin, or both. Patients with high blood sugar will typically experience polyuria (frequent urination), they will become increasingly thirsty (polydipsia) and hungry (polyphagia).

\section{Why is it called diabetes mellitus?}

Diabetes comes from Greek, and it means a "siphon". Aretus the Cappadocian, a Greek physician during the second century A.D., named the condition diabainein. He described patients who were passing too much water (polyuria) - like a siphon. The word became "diabetes" from the English adoption of the Medieval Latin diabetes.

In 1675, Thomas Willis added mellitus to the term, although it is commonly referred to simply as diabetes. Mel in Latin means "honey"; the urine and blood of people with diabetes has excess glucose, and glucose is sweet like honey. Diabetes mellitus could literally mean "siphoning off sweet water". 
In ancient China people observed that ants would be attracted to some people's urine, because it was sweet. The term "Sweet Urine Disease" was coined.

\section{Types of Diabetes}

Type 1 diabetes means that the immune system is compromised and the cells fail to produce insulin in sufficient amounts. There are no eloquent studies that prove the causes of type 1 diabetes and there are currently no known methods of prevention. Type 2 diabetes means that the cells produce a low quantity of insulin or the body can't use the insulin correctly. This is the most common type of diabetes, thus affecting $90 \%$ of persons diagnosed with diabetes. It is caused by both genetic factors and the manner of living.

Gestational diabetes appears in pregnant women who suddenly develop high blood sugar. In two thirds of the cases, it will reappear during subsequent pregnancies. There is a great chance that type 1 or type 2 diabetes will occur after a pregnancy affected by gestational diabetes.

\section{Causes of Diabetes}

Genetic factors are the main cause of diabetes. It is caused by at least two mutant genes in the chromosome 6 , the chromosome that affects the response of the body to various antigens. Viral infection may also influence the occurrence of type 1 and type 2diabetes. Studies have shown that infection with viruses such as rubella, mumps, hepatitis B virus, and cytomegalovirus increase the risk of developing diabetes. Currently, there is no permanent treatment for type 1 and type - 2diabetes. However, recent investigations and trials are being conducted, with Harvard and MIT reporting that they are close to finding a cure for type - 1diabetes.

\section{Methodology:}

A total of 50 people living in urban areas were selected for this survey, Study subjects were assessed using a case recording format including information for socioeconomic status, Life style, Methods of first diagnosis, blood pressure, Obesity, Heridity back round, physical activity (duration of work of $>90,60$ 90, 30-59, and <30 minutes per day as heavy, moderate, mild, and sedentary, resp.), diet, smoking, and alcohol use etc..,

\section{Results: Table showing the Questionnaire given in the survey:}

\begin{tabular}{|c|c|c|}
\hline $\begin{array}{c}\text { Characteris } \\
\text { tics }\end{array}$ & \multicolumn{2}{|c|}{$\begin{array}{c}\text { Total no. studied: } 50 \\
\text { Diabetes }\end{array}$} \\
\hline Gender & Females & Males \\
\hline \multirow[t]{2}{*}{ Age } & $<25 \quad>35$ & $<25>35$ \\
\hline & 29 & 19 \\
\hline \multirow[t]{2}{*}{$\begin{array}{l}\text { Hereditary/ } \\
\text { Gestation }\end{array}$} & $\begin{array}{l}\text { Hereditary } \\
\text { gestation }\end{array}$ & Hereditary \\
\hline & $20 \quad 21$ & 9 \\
\hline Stress & $35-$ & 15 \\
\hline \multirow{2}{*}{$\begin{array}{c}\text { Type of } \\
\text { Diabetics }\end{array}$} & Type -I Type- II & Type -I Type-II \\
\hline & $11 \quad 39$ & Nil $\quad 25$ \\
\hline Obesity & 37 & 13 \\
\hline $\begin{array}{l}\text { Physical } \\
\text { activities }\end{array}$ & 17 & 33 \\
\hline
\end{tabular}

\section{Discussion:}

From the survey results, we observed that females are more prone to diabetic during gestational period and due to stress in their job. This was increased exponentially due the loss of physical activities and food habits.

The results suggest that people with Type 1 diabetes were less likely to be provided with advice aimed at helping them to adopt a healthy lifestyle than those with Type 2 diabetes. Service users were more likely to always/almost always be given personal advice about food.

\section{Conclusion:}

Diabetes - type 2 is very difficult to cure. Also, there are no known methods of prevention, as this disease is mainly caused by genetic factors. There are no known cures at the moment, but recent advances in medical technology will enables to prolong the life of patients diagnosed with diabetes and improve their quality of life.

\section{Acknowledgement:}

Thanks to people participated in survey and shared their views to make this paper successful.

\section{References:}

1. An_Extensive_Survey_on_Diagnosis_of_Diabetes _Mellitus_in_Healthcare

2. 2020 vision - An overview of prospects for diabetes management and prevention in the next decade 
3. K. M. Venkat Narayan, P. Zhang, A. M. Kanaya et al., "Diabetes: the pandemic and potential solutions," in Disease Control Priorities in Developing Countries, D. T. Jamison, J. G. Breman, A. R. Measham et al., Eds., Oxford University Press, New York, NY, USA, 2nd edition, 2006 .
4. The National Survey of People with Diabetes Jenny Harris, Alice McGee, Fiona Andrews, John D'Souza and Kerry Sproston.

5. B. M. Popkin, "Urbanization, lifestyle changes and the nutrition transition," World Development.

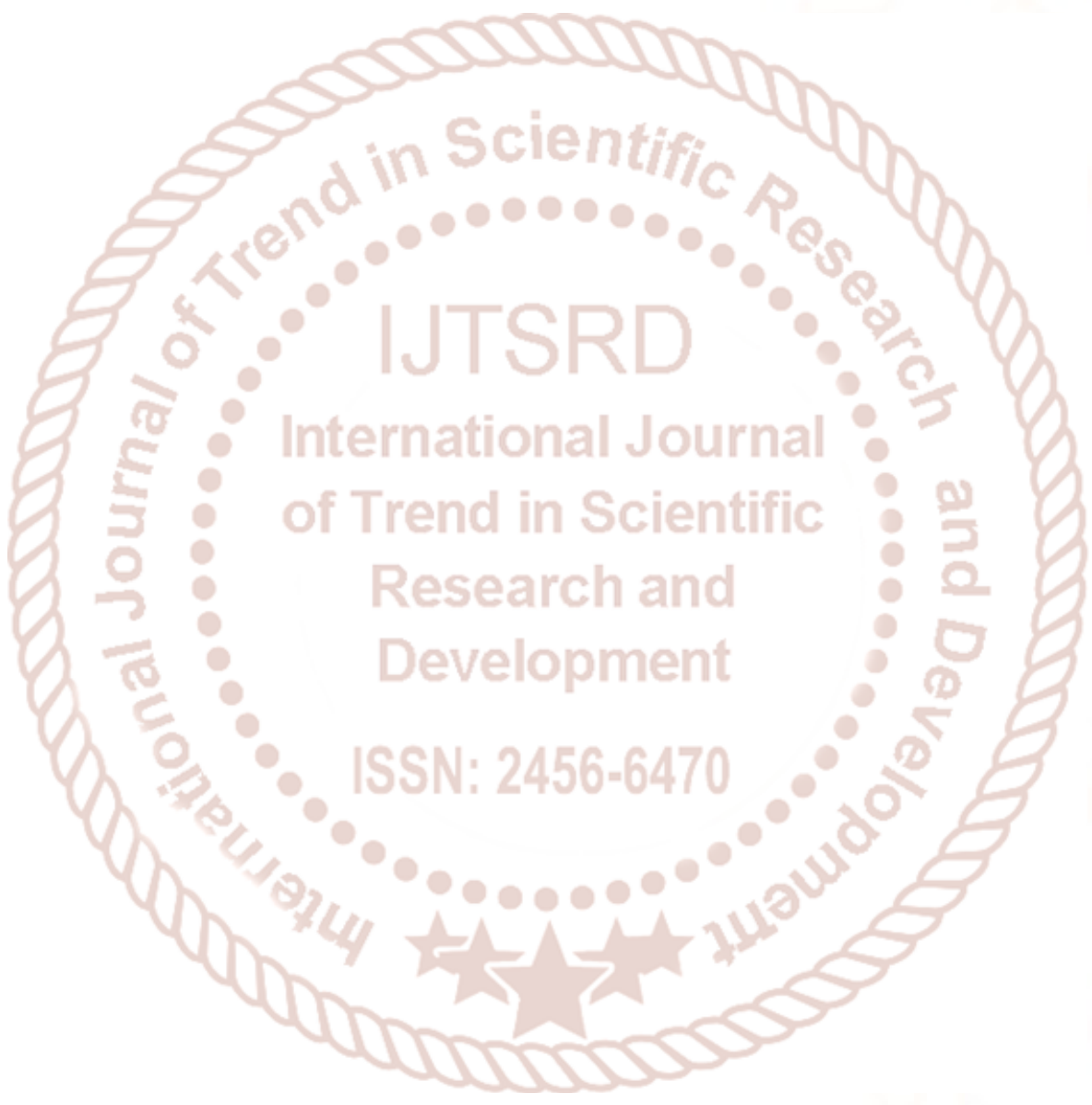

